\title{
En route formation of ion pairs at the ionic liquid-vacuum interface
}

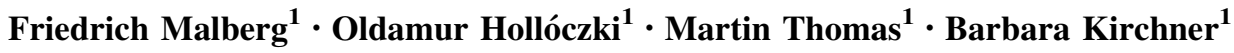

Received: 30 July 2015/Accepted: 8 August 2015/Published online: 26 August 2015

(c) The Author(s) 2015. This article is published with open access at Springerlink.com

\begin{abstract}
An increasing lack of single ion cation-anion associations (ion pairing) in ionic liquids suggests a structural motif that stands in contradiction to the single ion pair structure of their vapor phase, which was evidenced by different experimental and theoretical studies. Therefore, a structural rearrangement has to occur en route from the liquid to the vapor. In this study, we propose a detailed four-step evaporation mechanism for ionic liquids, providing a refined perspective on the theory of this process based on the connection between ion pairing and volatility. The process involves diffusion of ions from the bulk to the surface, where they float around until a well-defined ion pair is formed with a counterion, leading to the departure from the surface into the vacuum. To assess the validity of this scheme, we performed a series of classical and ab initio molecular dynamics simulations based on the most sophisticated methods and force fields available for ionic liquids.
\end{abstract}

Keywords Ionic liquid - Ion pair · Gas phase ·

Evaporation

This paper is dedicated to Professor Magdolna Hargittai on the occasion of her 70th birthday.

\section{Barbara Kirchner}

kirchner@thch.uni-bonn.de

1 Mulliken Center for Theoretical Chemistry, Institut für Physikalische und Theoretische Chemie, Universität Bonn, Beringstr. 4, 53115 Bonn, Germany

\section{Introduction}

Ionic liquids (ILs) had been often described as "nonvolatile" replacement for organic solvents [1-4]; however, in processes where other possible advantageous properties of ILs are utilized, the low vaporizability became a limiting obstacle in the effective purification via distillation. As a real breakthrough in this issue, Earle et al. [5] showed that under rather harsh conditions ILs can be distilled. Accordingly, many subsequent studies aimed to understand the vapor and the vapor-liquid interface of ILs [6-10], to have a better insight into the mechanism of vaporization. Based on line-of-sight mass spectrometry and ultraviolet photoelectron spectroscopy of ionic liquid vapor, a vaporization via the formation of single ion pairs was evidenced $[6,11,12]$. On the other hand, a lack of single cation-anion associations (no specific cation-anion pairing) within the liquid [13-18] suggests a different structural motif than in the vapor, rising the question how the transfer between these different structures takes place. It was pointed out recently by Austen Angell et al. [4] that ionic liquids indicating more pairing up of ions in the liquid were the ones observed to be distilled more easily. Considering these fundamentally different structural features, the process of vaporization is apparently not as trivial as for molecular solvents, and significant structural rearrangement has to occur en route from the bulk to the vapor. The vaporization process, therefore, should involve not only the diffusion to the surface, but also the formation of the vaporizable entity, and-since it consists of two molecules, and hence it is more flexible than the molecular solventsalso its rearrangement in the gas phase may be of great importance $[19,20]$.

Thus, we propose here a detailed four-step evaporation mechanism for ILs (see Fig. 1), providing a refined 
Fig. 1 Left Possible multistep mechanism describing the complex evaporation process of ionic liquids, from the "melange" [13] of ions in the bulk as observed in our study, via the formation of an ion pair at the surface and the subsequent evaporation, to the rearranged and stabilized vapor [14]. Right Snapshots of MD simulations, reproducing the mechanism; Blue cation, red anion (Color figure online)

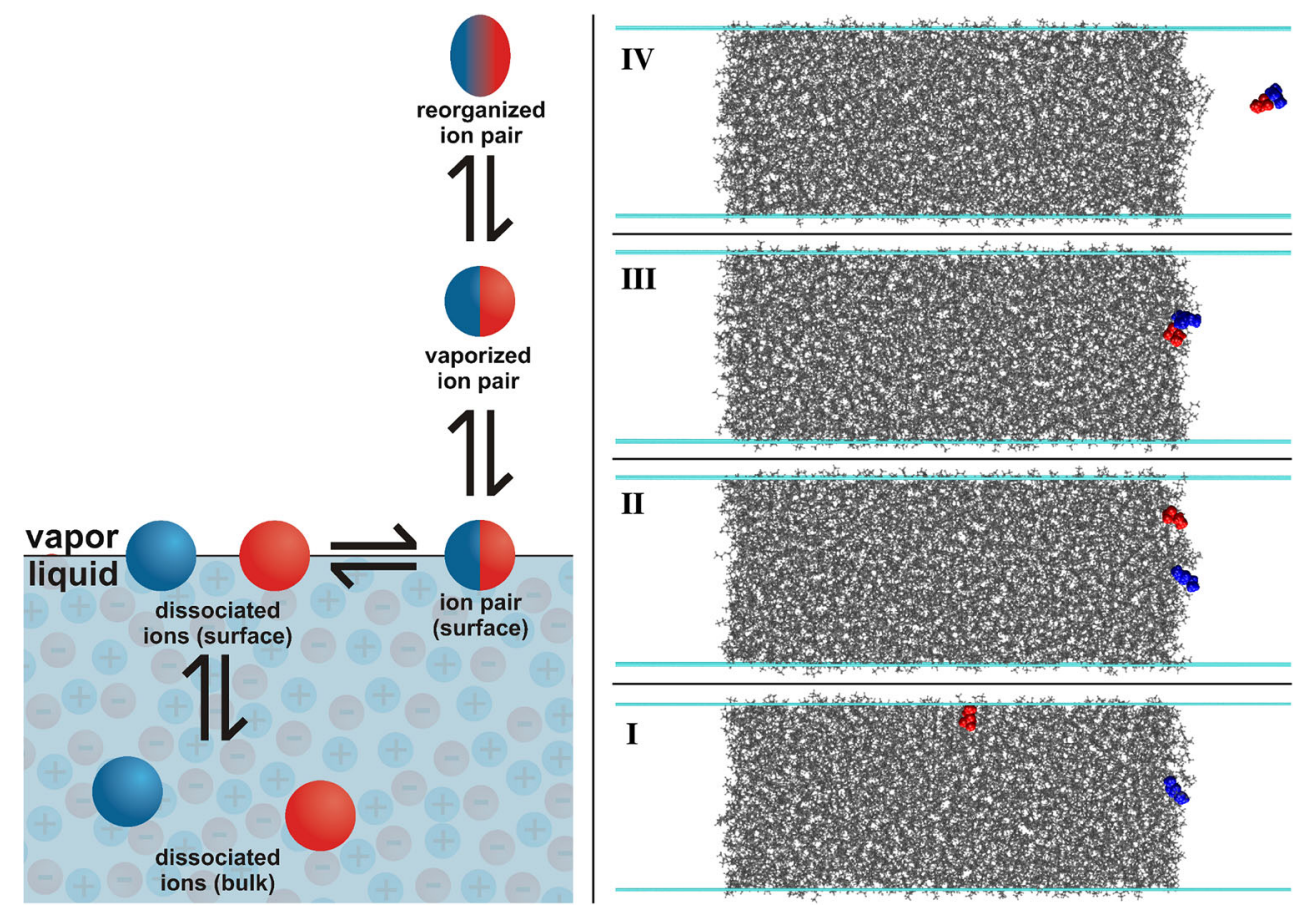

perspective for the theory of this process. To assess the validity of this scheme, we performed a series of classical and $a b$ initio molecular dynamics simulations on the 1-ethyl-3-methylimidazolium ethylsulfate ionic liquid and the 1-ethyl-3-methylimidazolium bis(trifluoromethylsulfonyl)imide ionic liquid [21]. First, to obtain a qualitative picture, in an ensemble that contains an IL surface (described elsewhere [22]), a chosen ion was dragged out of the liquid through the interface by applying a constant force to it. The resulting trajectory was in very good agreement with the general picture. The ion first diffuses to the surface, where it is floating for a certain time, and after forming a well-defined ion pair with a counterion, they depart from the surface to the vacuum together (Fig. 1).

\section{Results}

The cornerstone of the above-described mechanistic picture is the gradual change in the ion pairing from the liquid to the vapor, which should be at a maximum either at the surface, or very close to it. Accordingly, at the interface region of the IL there should be more ion pair-like structures (IPs), than in the bulk phase. Since one of the reasons that there are less (long-lived) ion pairs in the bulk is that there are several counterions surrounding one particle [2326], this change in ion pairing can be tracked indirectly by monitoring the coordination number from the bulk to the surface (Fig. 2).
Indeed, the bulk and the interface region can clearly be distinguished in Fig. 2 for both ILs. In the bulk region, both the cations and anions have $\sim 6.5$ and $\sim 7.5$ counterions, respectively, in their first solvation shell, which at a distance of ca. $1100 \mathrm{pm}$ from the surface starts to drop, and reaches $\sim 3.5$ counterions for the anions at the surface in both ILs, i. e. approximately half of the solvent shell is missing. As has been observed before for $\left[\mathrm{C}_{2} \mathrm{C}_{1} \mathrm{im}\right]\left[\mathrm{C}_{2} \mathrm{SO}_{4}\right]$ [22], the cations and the anions are not homogeneously distributed at the interface. The surface is mainly covered by the anions, which is reflected by the contribution of neighboring cations between 7100 and $7200 \mathrm{pm}$ (see Fig. 2); thus, the center of mass of the anions is closer to the vacuum than the center of mass of the cations. In addition, up to ca. 1000 pm into the bulk (7200-8200 pm) there are somewhat less cations in the liquid (red bars height smaller than black bars height). This shortage on cations is made up for by their slight excess in the following 1000 pm (8200-9200 pm), which afterward flattens into the completely equal coordination number of both ions. For $\left[\mathrm{C}_{2} \mathrm{C}_{1} \mathrm{im}\right]\left[\mathrm{NTf}_{2}\right]$, the picture is slightly different. The ions are more homogeneously distributed at the surface [27] (contributions of neighboring cations and anions between 10,700 and $10,800 \mathrm{pm}$ ). After this, the shortage on cations in the interface region up to ca. $1000 \mathrm{pm}$ into the bulk (10,900-11,700 pm) occurs which is finally followed by the cation excess phase and then by the usual bulk behavior. Interestingly, according to these results the surface region of the ILs is rather thin, and after ca. 1000 pm into the bulk its effect on the coordination number is small, 

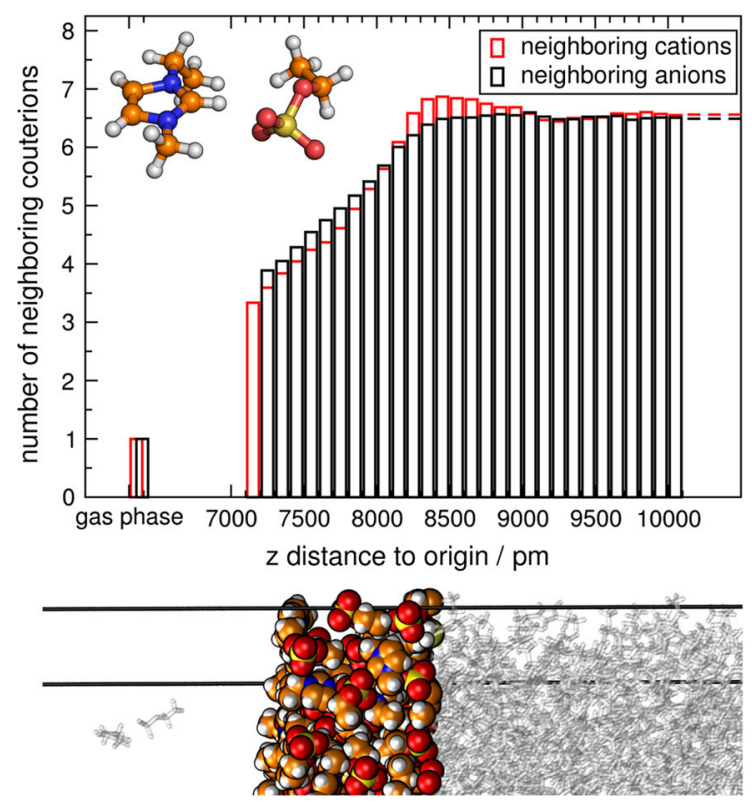

Fig. 2 Histograms of neighboring counterions (top $\left[\mathrm{C}_{2} \mathrm{C}_{1} \mathrm{im}\right]\left[\mathrm{C}_{2} \mathrm{SO}_{4}\right]$; bottom $\left.\left[\mathrm{C}_{2} \mathrm{C}_{1} \mathrm{im}\right]\left[\mathrm{NTf}_{2}\right]\right)$ and snapshot of MD simulation to distinguish gas phase, interface region and bulk region; black neighboring

and after $2000 \mathrm{pm}$ into the bulk it is not observable at all. It is also worth to point out that beyond this "layering" of the different ions, the anion and cation have other microscopic properties that show clear differences. For example, it has been shown that the cations have larger mobilities in ILs compared to the anions $[28,29]$, even if the latter particle is significantly smaller in size [30].

Ion pairing [31], however, can also be defined via considering dynamical criteria, as has been proposed by Zhao et al. [32] The two descriptors that may aid assessing the presence of IPs are how far and for how long two neighboring oppositely charged particles travel together in the solution. Hence, these descriptors may not only aid in the quantitative characterization of an ion pair but more importantly also in their qualitatively characterization. If the above-described changes in ion pairing are valid, then these dynamic criteria should also exhibit significant changes for the bulk and for the surface. In Fig. 3, it can be seen that while the distribution of the IPs' lifetime only slightly changes in these two regions, their path that they move together is considerably elongated at the surface (bottom) compared to the bulk (top) for both ILs. In other words, although they remain neighbors for the same time at both the surface and in the bulk of the ILs, during this time they move more, thus, they "survive" more collisions with the surrounding particles. Hence, also these findings can be interpreted as a qualitative change in ion pairing at the surface of ILs, similarly to the picture achieved from investigating the histograms of neighboring counterions (see Fig. 2).

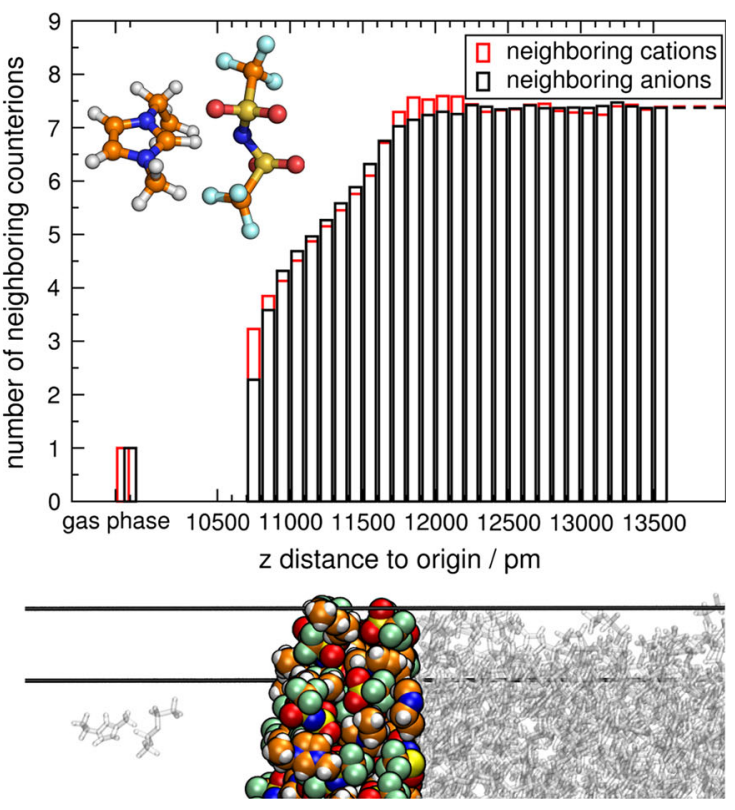

anions to reference cations; red neighboring cations to reference anions. For more information on analysis see "Computational details"

Beyond the mere fact that the ion pairing [31] is qualitatively different at these two regions, being important in the evaporation process, this more restrictive association should also have structural consequences. In Fig. 4, averages of three characteristic distances are shown as approaching the surface from the bulk, and for the single (gas phase) ion pair for both ILs. Similarly to the coordination numbers, a gradual change can be observed in the average conformation, from about $1200 \mathrm{pm}$ below the surface for the $\left[\mathrm{C}_{2} \mathrm{C}_{1} \mathrm{im}\right]\left[\mathrm{C}_{2} \mathrm{SO}_{4}\right]$ IL. Throughout this interval, the C7'(A)CoR distances increase, which means that the anion's ethyl group moves away from the cation's ring and is elongated the most in the gas phase [19]. This displacement is in accordance with the slight decrease in the distances between the centers of charge $(\mathrm{CoC})$; thus, the charged, and therefore more interacting sulfate oxygen atoms turn to face the cationic ring, while the anionic side chain is moving away from it. In the gas phase, where no other ions are present to provide further interactions, the $\mathrm{CoC}(\mathrm{A})-\mathrm{CoC}(\mathrm{C})$ distance is minimized, which also brings the centers of mass closer, seemingly breaking the increasing trend in their distance from the bulk to the surface.

For the $\left[\mathrm{C}_{2} \mathrm{C}_{1} \mathrm{im}\right]\left[\mathrm{NTf}_{2}\right] \mathrm{IL}$, the gradual change is not as dominant as for the $\left[\mathrm{C}_{2} \mathrm{C}_{1} \mathrm{im}\right]\left[\mathrm{C}_{2} \mathrm{SO}_{4}\right] \mathrm{IL}$. Structural changes start from about $600 \mathrm{pm}$ below the surface. Throughout this smaller interval, similar but less extreme changes in the characteristic distances are observed than the changes in the $\left[\mathrm{C}_{2} \mathrm{C}_{1} \mathrm{im}\right]\left[\mathrm{C}_{2} \mathrm{SO}_{4}\right]$ IL. The nearest $\mathrm{Cl}^{\prime} / 2^{\prime}(\mathrm{A})-\mathrm{CoR}$ distances increase slightly, being in accordance with a slight increase in the center of mass ( $\mathrm{CoM})$ distance, 

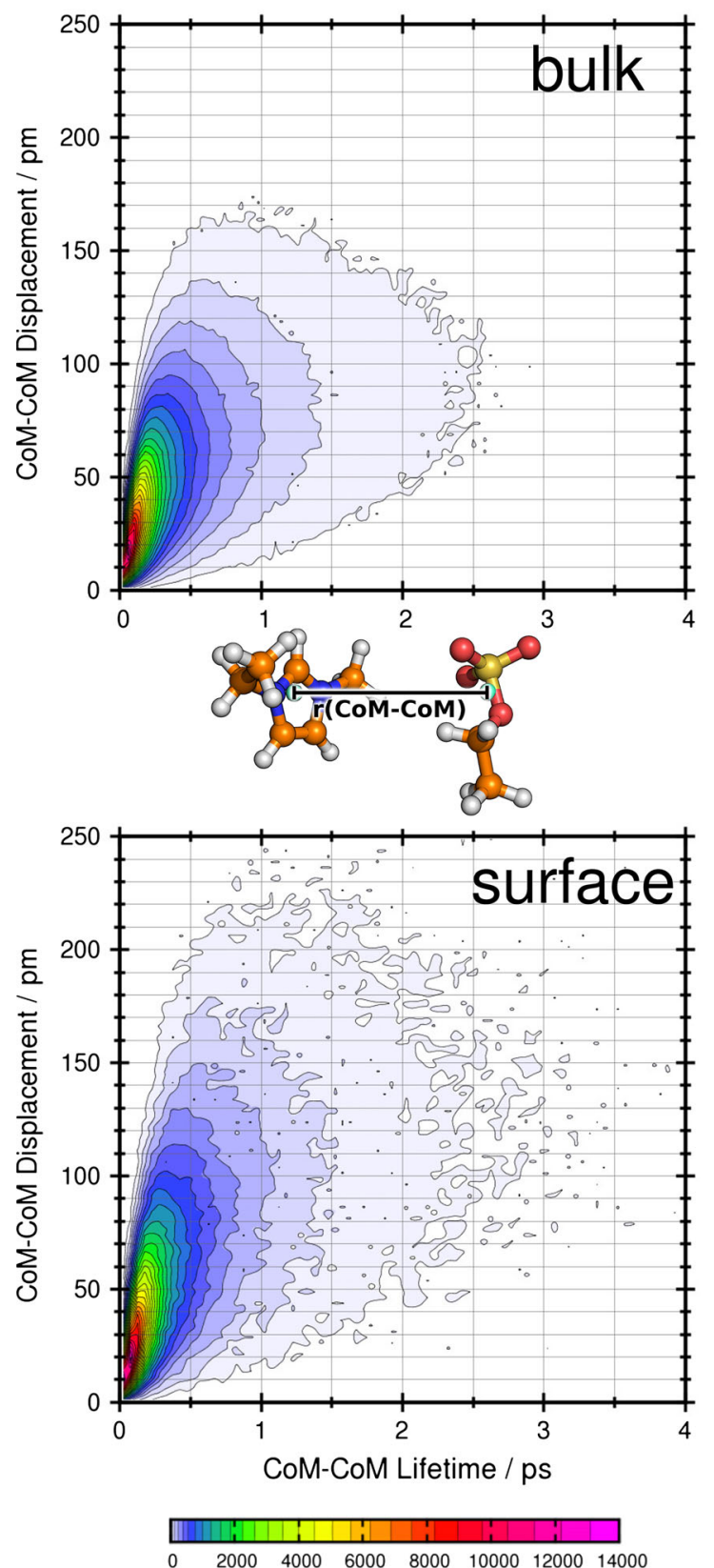

Fig. 3 Combined distribution function (CDF) plotting the CoM-CoM displacement of an ion pair during its lifetime calculated for being next neighbors with respect to the CoM. Left $\left[\mathrm{C}_{2} \mathrm{C}_{1} \mathrm{im}\right]\left[\mathrm{C}_{2} \mathrm{SO}_{4}\right]$. Right $\left[\mathrm{C}_{2} \mathrm{C}_{1} \mathrm{im}\right]\left[\mathrm{NTf}_{2}\right]$. Top CDF calculated for ions of the bulk regions,

whereas the center of charge $(\mathrm{CoC})$ distance initially decreases and then slightly increases in the direct vicinity of the surface, indicating a final reorganization of the ions at the interface. In the gas phase, the $\mathrm{CoC}(\mathrm{A})-\mathrm{CoC}(\mathrm{C})$ distance is again minimized, therefore, reducing the centers of mass and the $\mathrm{C} 1^{\prime} / 2$ '(A)-CoR distances, seemingly breaking the increasing trend in their distance from the bulk to the surface as well. These differences for both ILs can be attributed on the one hand to the different underlying chemical structure, but on the other hand also to the more

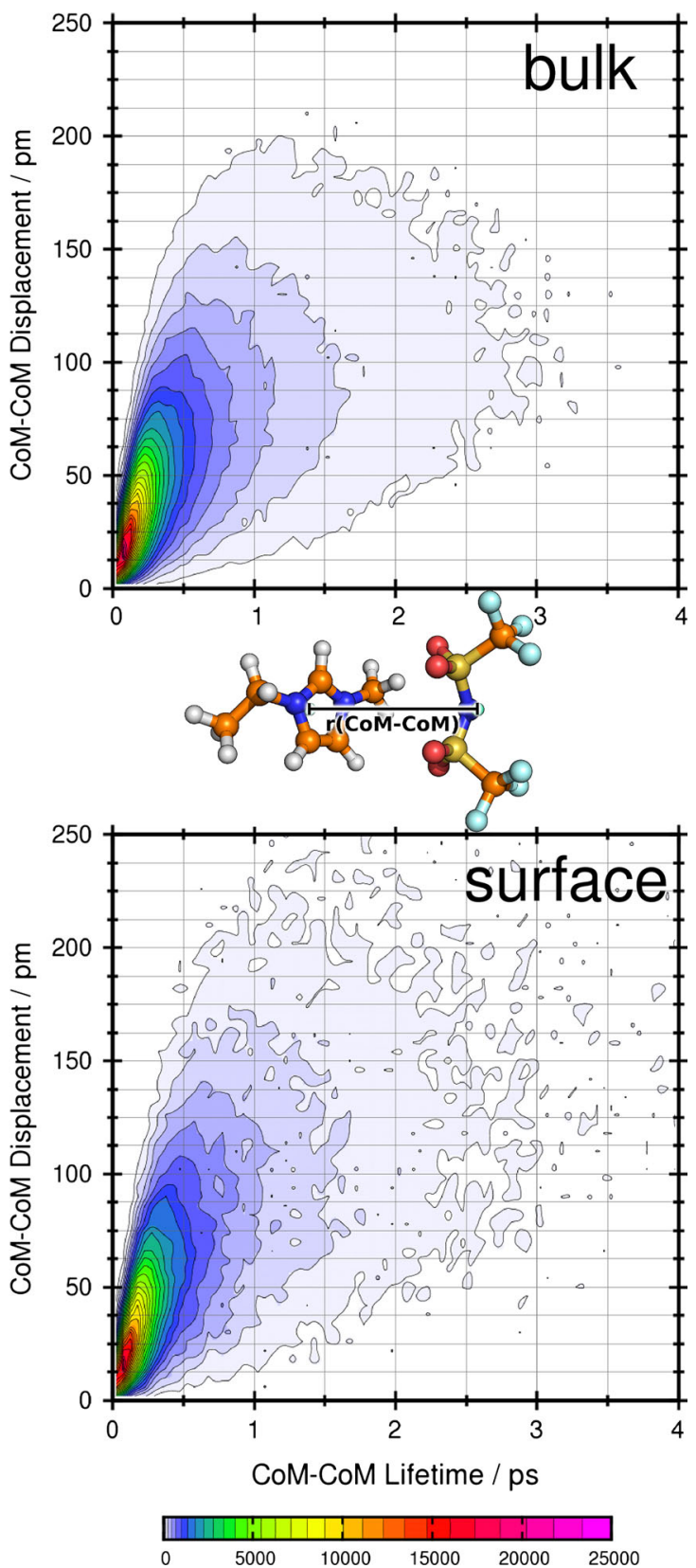

neglecting ions of the surface regions of the slabs. Bottom CDF calculated only for ions situated in both surface regions of the slab, neglecting all ions from the bulk regions

homogenous distribution of $\left[\mathrm{NTf}_{2}\right]$-anion and $\left[\mathrm{C}_{2} \mathrm{C}_{1} \mathrm{im}\right]-$ cation at the surface in the one IL while almost only $\left[\mathrm{C}_{2} \mathrm{SO}_{4}\right]$-anions are present at the surface for the other IL.

\section{Conclusion}

According to the above data, it can be seen that the arrangement of the IL ions changes from the bulk to the surface gradually more similar to that in the gas phase, 

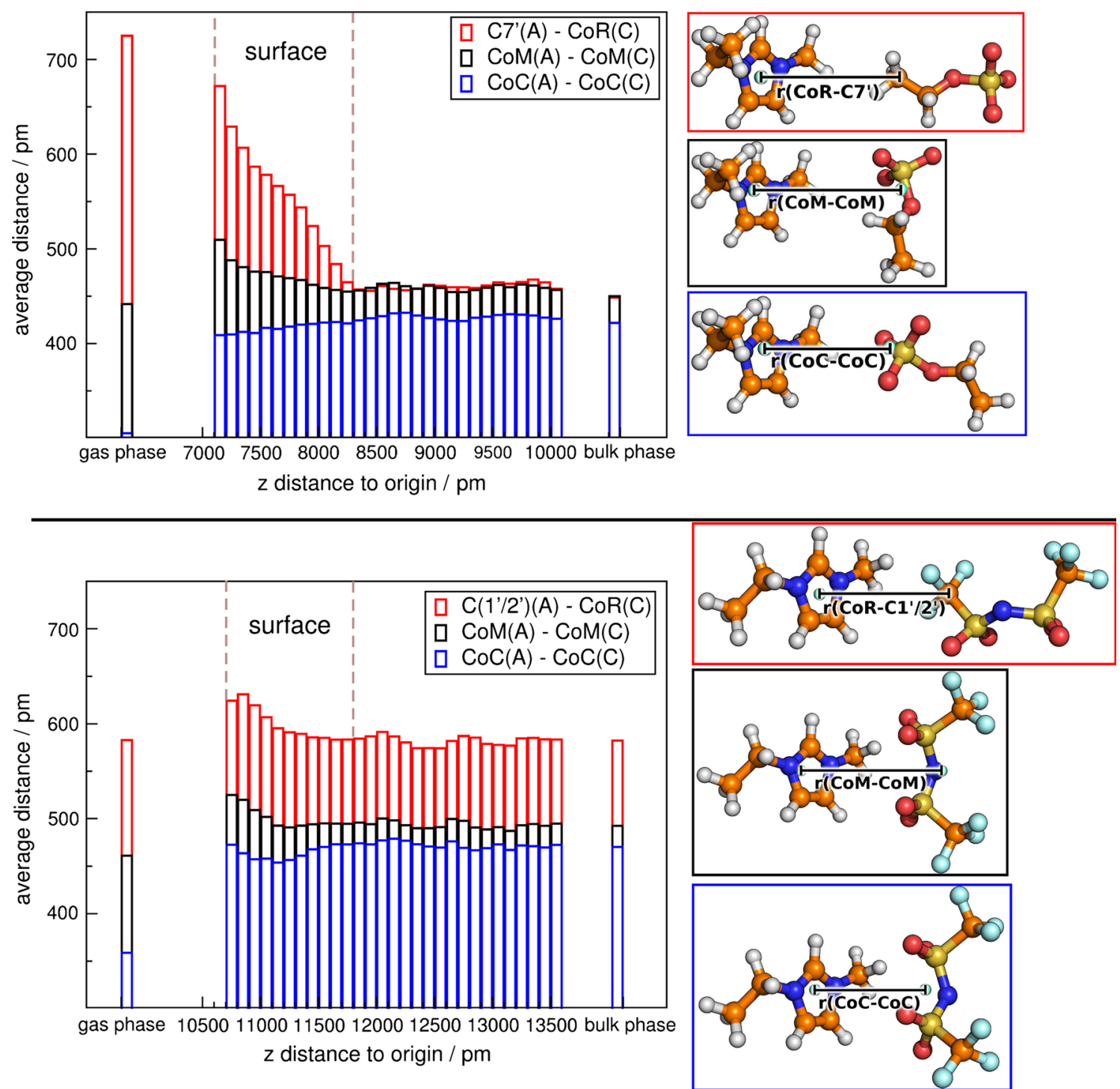

Fig. 4 Top $\left(\left[\mathrm{C}_{2} \mathrm{C}_{1} \mathrm{im}\right]\left[\mathrm{C}_{2} \mathrm{SO}_{4}\right]\right)$ : Histogram of the average distance between the terminal carbon atom of the anion $\mathrm{C}^{\prime}$ ' to the center of the imidazolium-ring $(\mathrm{CoR})$, between the center of mass $(\mathrm{CoM})$ of the anion (A) and cation (C) and between the center of charges $(\mathrm{CoC})$ of anion (A) and cation (C). Bottom $\left(\left[\mathrm{C}_{2} \mathrm{C}_{1} \mathrm{im}\right]\left[\mathrm{NTf}_{2}\right]\right)$ : Histogram of the average distance between the nearest terminal carbon atoms of the

preparing the ion pair for departure, thus, evaporation. This involves the formation of ion pairs in the surface, and also the conformational alignment of the two ions within these ion pairs. After evaporation, the missing solvation of the ion pair allows for further, more extreme rearrangements. Hence, these data completely underpin the multistep mechanism shown in Fig. 1, providing a refined viewpoint in the theory of vaporization in general. We believe this scheme is necessary for the proper description of the corresponding process, and thus, enhances the advance in the field of IL design. anion $\mathrm{C} 1$ '/2' to the center of the imidazolium-ring (CoR), between the center of mass $(\mathrm{CoM})$ of the anion $(\mathrm{A})$ and cation $(\mathrm{C})$ and between the center of charges $(\mathrm{CoC})$ of anion $(\mathrm{A})$ and cation $(\mathrm{C})$. To obtain the average distance, we determined the distance distribution between next neighboring observed atoms and calculated their average distance, depending on the specific regions

\section{Computational details}

We investigated 1024 ion pairs $(\sim 32,000$ atoms $)$ of $\left[\mathrm{C}_{2} \mathrm{C}_{1} \mathrm{im}\right]\left[\mathrm{C}_{2} \mathrm{SO}_{4}\right]$ and 906 ion pairs ( $\sim 31,000$ atoms $)$ of $\left[\mathrm{C}_{2} \mathrm{C}_{1} \mathrm{im}\right]\left[\mathrm{NTf}_{2}\right]$ separately in a periodic box, where the normal direction to the surface was extended to 27,500 and $35,000 \mathrm{pm}$, respectively, so the liquid slab occupies $\sim 12,000 \mathrm{pm}$ in the middle with two equivalent liquidvacuum interfaces. The initial configuration was constructed by placing together two cubic boxes with 512 ion pairs and 453 ion pairs, respectively, which were 
equilibrated for $1 \mathrm{~ns}$ at constant NPT and $T=423 \mathrm{~K}$ with a time step of 2 fs to obtain the final density of these liquids. Equilibration of the initial configurations took $1 \mathrm{~ns}$ with a time step of $2 \mathrm{fs}$ in the NPT ensemble, after which the systems were run for $1 \mathrm{~ns}$ to allow the interface to equilibrate. The production run was $2 \mathrm{~ns}$ with periodic boundary conditions coupled to Nosé-Hoover thermostats $[33,34]$ to keep the temperature constant at $423 \mathrm{~K}$ (constant NVT). Afterwards, a constant force in opposite $z$ directions (normal to the surfaces) was put on arbitrary chosen cation and anion to obtain a qualitative picture of the mechanism at the surface. The systems were simulated via molecular dynamics using the DL_POLY package [35] and the LAMMPS package $[36,37]$. The trajectories were evaluated with our software TraVis [38-41]. The GRACE program [42] was used to plot the $2 \mathrm{D}$ diagrams, and the contour plots were created with gunplot [43].

To obtain the number of neighboring counterions for Fig. 2, we determined the radial distribution functions of the center of mass of the reference ion to the center of mass of the observed ions and integrated these functions to the first minimum in the bulk, which is $\sim 800 \mathrm{pm}$ (top) and $\sim 920 \mathrm{pm}$ (bottom), respectively. The reference ions were explicitly chosen from regions with a width of $100 \mathrm{pm}$ in the normal direction to the interface. The slab of the ionic liquids extend over $12,000 \mathrm{pm}$ in $z$-direction, while the whole box is $27,500 \mathrm{pm}$ (top) wide and $35,000 \mathrm{pm}$ (bottom) wide, respectively. Therefore at approximately $7000 \mathrm{pm}$ (top) and 10,500 pm (bottom), one surface of the slab is expected. Note: These histograms were done for a small part of the slab (3000 pm) and not for the whole slab $(12,000 \mathrm{pm})$.

Acknowledgments Financial supported by the DFG through the project SPP 1708 is gratefully acknowledged. The authors would like to thank Alfonso S. Pensado for helpful discussions.

Open Access This article is distributed under the terms of the Creative Commons Attribution 4.0 International License (http://crea tivecommons.org/licenses/by/4.0/), which permits unrestricted use, distribution, and reproduction in any medium, provided you give appropriate credit to the original author(s) and the source, provide a link to the Creative Commons license, and indicate if changes were made.

\section{References}

1. Welton T (1999) Chem Rev 99:2071-2084

2. Hallett JP, Welton T (2011) Chem Rev 111:3508-3576

3. Welton T (2004) Coord Chem Rev 248:2459-2477

4. Angell Austen C, Ansari Y, Zhao Z (2012) Faraday Discuss 154:9-27

5. Earle MJ, Esperança JMSS, Gilea MA, Canongia Lópes JN, Rebelo LPN, Magee JW, Seddon KR, Widegren JA (2006) Nature 439:831-834
6. Armstrong JP, Hurst C, Jones RG, Licence P, Lovelock KRJ, Satterley CJ, Villar-Garcia IJ (2007) Phys Chem Chem Phys 9:982-990

7. Zaitsau DH, Kabo GJ, Strechan AA, Paulechka YU, Tschersich A, Verevkin SP, Heintz A (2006) J Phys Chem A 110:7303-7306

8. Esperança JMSS, Canongia Lópes JN, Tariq M, Santos LM, Magee JW, Rebelo LPN (2010) J Chem Eng Data 55:3-12

9. Lovelock KRJ, Deyko A, Licence P, Jones RG (2010) Phys Chem Chem Phys 12:8893-8901

10. Lovelock KRJ (2012) Phys Chem Chem Phys 14:5071-5089

11. Strasser D, Goulay F, Kelkar MS, Maginn EJ, Leone SR (2007) J Phys Chem A 111:3191-3195

12. Leal JP, Esperança JMSS, Minas da Piedade ME, Canongia Lópes JN, Rebelo LPN, Seddon KR (2007) J Phys Chem A 111:6176-6182

13. Hallett JP, Liotta CL, Ranieri G, Welton T (2009) J Org Chem 74:1864-1868

14. Lui MY, Crowhurst L, Hallett JP, Hunt PA, Niedermeyer H, Welton T (2011) Chem Sci 2:1491-1496

15. Lynden-Bell RM (2010) Phys Chem Chem Phys 12:1733-1740

16. Perkin S, Salanne M, Madden P, Lynden-Bell R (2013) Proc Natl Acad Sci USA 110:E4121

17. Perkin S, Salanne M (2014) J Phys Condens Matter 26:280301

18. Lee AA, Vella D, Perkin S, Goriely A (2015) J Phys Chem Lett 6:159-163

19. Malberg F, Pensado AS, Kirchner B (2012) Phys Chem Chem Phys 14:12079-12082

20. Malberg F, Brehm M, Hollóczki O, Pensado AS, Kirchner B (2013) Phys Chem Chem Phys 15:18424-18436

21. Kirchner B, Hollóczki O, Canongia Lopes JN, Pádua AAH (2015) WIREs Comput Mol Sci 5:202-214

22. Paredes X, Fernández J, Pádua AAH, Malfreyt P, Malberg F, Kirchner B, Pensado AS (2012) J Phys Chem B 116:14159-14170

23. Hardacre C, Holbrey JD, McMath SJ, Bowron DT, Soper AK (2003) J Chem Phys 118:273-278

24. Deetlefs M, Hardacre C, Nieuwenhuyzen M, Pádua AAH, Sheppard O, Soper AK (2006) J Phys Chem B 110:12055-12061

25. Zahn S, Thar J, Kirchner B (2010) J Chem Phys 132:124506

26. Zhang Y, Maginn EJ (2012) Phys Chem Chem Phys 14:12157-12164

27. Nakajima K, Ohno A, Hashimoto H, Suzuki M, Kimura K (2010) J Chem Phys 133:044702

28. Tokuda H, Hayamizu K, Ishii K, Susan MABH, Watanabe M (2004) J Phys Chem B 108:16593-16600

29. Tokuda H, Hayamizu K, Ishii K, Susan MABH, Watanabe M (2005) J Phys Chem B 109:6103-6110

30. Rupp A, Roznyatovskaya N, Scherer H, Beichel W, Klose P, Sturm C, Hoffmann A, Tübke J, Koslowski T, Krossing I (2014) Chem Eur J 20:9794-9804

31. Hollóczki O, Malberg F, Welton T, Kirchner B (2014) Phys Chem Chem Phys 16:16880-16890

32. Zhao W, Leroy F, Heggen B, Zahn S, Kirchner B, Balasubramanian S, Müller-Plathe F (2009) J Am Chem Soc 131:15825-15833

33. Nosé S (1984) J Chem Phys 81:511

34. Nosé S (1984) Mol Phys 52:255-268

35. Smith W, Forester T, Todorov I (2012) The DL\_POLY Classic User Manual

36. Plimpton SJ (1995) Comput Phys 117:1-19

37. LAMMPS WWW site:, http://lammps.sandia.gov

38. Brehm M, Kirchner B (2011) J Chem Inf Model 51:2007-2023

39. Thomas M, Brehm M, Fligg R, Vöhringer P, Kirchner B (2013) Phys Chem Chem Phys 15:6608-6622

40. Thomas M, Brehm M, Hollóczki O, Kelemen Z, Nyulśzi L, Pasinszki T, Kirchner B (2014) J Chem Phys 141:024510 
41. Thomas M, Brehm M, Kirchner B (2015) Phys Chem Chem Phys $17: 3207-3213$

42. Grace (c) 1996-2008 Grace Development Team, see http:// plasma-gate.weizmann.ac.il/Grace
43. Williams T, Kelley C et al. (2012) Gnuplot 4.6: an interactive plotting program. http://gnuplot.sourceforge.net/ 